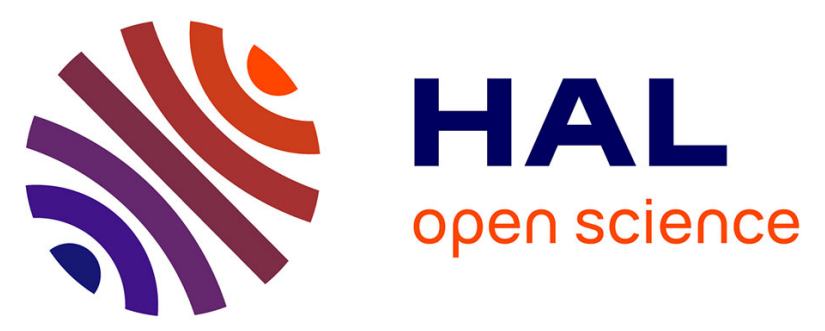

\title{
Zr precipitation kinetics in irradiated fuel dissolution solution by TIMS and ICP-MS: a combined study
}

Sarah Baghdadi, Alexandre Quemet, Eric Esbelin, Yohann Manidren, Sophie

Gracia, Vincent Dalier, Rémi Poinsignon-Jacquemin, • Laurent Huyghe, Emilie Buravand, Jean-Luc Dautheribes, et al.

\section{To cite this version:}

Sarah Baghdadi, Alexandre Quemet, Eric Esbelin, Yohann Manidren, Sophie Gracia, et al.. Zr precipitation kinetics in irradiated fuel dissolution solution by TIMS and ICP-MS: a combined study. Journal of Radioanalytical and Nuclear Chemistry, 2017, 314 (3), pp.2377-2382. 10.1007/s10967-017-5602-6 . cea-02267579

\section{HAL Id: cea-02267579 \\ https://hal-cea.archives-ouvertes.fr/cea-02267579}

Submitted on 19 Aug 2019

HAL is a multi-disciplinary open access archive for the deposit and dissemination of scientific research documents, whether they are published or not. The documents may come from teaching and research institutions in France or abroad, or from public or private research centers.
L'archive ouverte pluridisciplinaire HAL, est destinée au dépôt et à la diffusion de documents scientifiques de niveau recherche, publiés ou non, émanant des établissements d'enseignement et de recherche français ou étrangers, des laboratoires publics ou privés. 


\title{
$\mathrm{Zr}$ precipitation kinetics in irradiated fuel dissolution solution by TIMS and ICP-MS: a combined study
}

\author{
Sarah Baghdadi ${ }^{1}$ (D) Alexandre Quémet ${ }^{1} \cdot$ Eric Esbelin $^{1} \cdot$ Yohann Manidren $^{1}$. \\ Sophie Gracia ${ }^{1}$ - Vincent Dalier ${ }^{1} \cdot$ Rémi Poinsignon-Jacquemin $^{1}$ - Laurent Huyghe ${ }^{1}$. \\ Emilie Buravand $^{1} \cdot$ Jean-Luc Dautheribes $^{1} \cdot$ Cédric Rivier $^{1}$
}

Received: 15 September 2017

(C) Akadémiai Kiadó, Budapest, Hungary 2017

\begin{abstract}
This study presents the combined analysis of leftover zirconium in irradiated fuel dissolution solution through time. Thermo-ionisation mass spectrometry was used to analyse the kinetics start and final aliquots with uncertainties lower than 3\%, while inductively coupled plasma-mass spectrometry (ICP-MS) was used for intermediary aliquots. In order to obtain low uncertainties using ICP-MS, dissolution solutions were spiked with lutetium, used as a process tracer, in order to perform a relative analysis. The analytical parameters were optimised and uncertainties were lower than $3 \%$ for real nuclear samples. This method shows the input of ICP-MS for concentration evolutions determination.
\end{abstract}

Keywords Zirconium · ICP-MS · TIMS · Relative analysis $\cdot$ Spike $\cdot$ Irradiated nuclear fuel

\section{Introduction}

Zirconium is present at different stages of the nuclear fuel cycle, as it is a component of the PWR fuel rod cladding [1] and can also be found as a fission product [2]. In such case its isotope composition is not natural. In the recycling process, fuel rods are dissolved in concentrated nitric acid. Depending on chemical conditions, zirconium tends to precipitate through time in presence of molybdenum in nitric acid [3-7].

Alexandre Quémet

alexandre.quemet@cea.fr

1 Nuclear Energy Division, Research Department of Mining and Fuel Recycling, CEA, Gif-sur-Yvette, France
When wanting to study $\mathrm{Zr}$ precipitation kinetics in nitric acid, many samples are collected for analysis (at least seven, along the course of the reaction). Some analytical techniques are available directly in hot cells such as X-ray Fluorescence (XRF) [8], but in order to determine the zirconium isotope composition and concentration with uncertainties lower than $3 \%$, it is necessary to use either thermo-ionisation mass spectrometry (TIMS) or multi collection inductively coupled plasma mass spectrometry (MC-ICP-MS) [9, 10]. The ATALANTE analyses laboratory (L2AT) only owns a nuclearized TIMS in a glove box, needing important dilution factors because of the high level of radiations the samples present.

The zirconium analysis method by TIMS for nuclear samples was presented by Quemet et al. [10], and necessitates to spike the samples in the shielded cell and perform separations before being able to analyse them as after the amount-of substance needed and the uncertainties required are not compatible with important dilution factors. Here, fourteen samples from two different kinetics experiments were supposed to be aliquoted. The average duration for a single sample analysis is 15 working days and even though it can be mutualised, it is difficult to use only this method to follow the $\mathrm{Zr}$ precipitation kinetics over its entire course. It was necessary to propose a new analytical method not necessitating TIMS analysis only.

This paper proposes a method using TIMS analyses of the first and final samples of the kinetics and an ICP-MS relative analyses for the kinetics core samples. Only four samples are going to be analysed using the TIMS method, all the other are going to be analysed using the ICP-MS method developed here. Optimisation experiment and development parameters are going to be explained and results obtained on two different kinetics experiments be presented. 


\section{Experimental}

\section{Reagents}

Nitric $\left(w_{\mathrm{t}}=67 \%\right.$, Prolabo, USA $)$ and hydrofluoric $\left(w_{\mathrm{t}}=67 \%\right.$, Prolabo, USA) acids were of Ultrapure Normatom grade. Oxalic acid was purchased from Fluka (USA). Lutetium, zirconium, molybdenum and ytterbium in nitric acid standard solutions $\left(1000 \mu \mathrm{g} \mathrm{mL}^{-1}\right)$ were purchased from SPEX $^{\circledR}$ (USA). Deionised water was provided by a MilliQ system (resistivity: $18.2 \mathrm{M} \Omega \mathrm{cm}$, Millipore, Milford, MA, USA).

Initial solutions consisted of $6.6 \mathrm{~mol} \mathrm{~L}^{-1}$ nitric acid, prepared by diluting concentrated $\mathrm{HNO}_{3}$ in deionised water volumetrically. Stabilisation solution consisted of $5 \mathrm{~mol} \mathrm{~L}^{-1}$ nitric acid prepared the same way.

ICP-MS dilution solution consisted of $(2 \% / 0.1 \%)\left(w_{\mathrm{t}} / w_{\mathrm{t}}\right)$ $\mathrm{HNO}_{3} / \mathrm{HF}$ and were prepared by volumetric dilution in deionised water. Samples were spiked with $10 \mu \mathrm{g} \mathrm{L}^{-1}$ ytterbium. ICP-MS rinse solution consisted of $(10 \% / 0.1 \%)$ $\left(w_{\mathrm{t}} / w_{\mathrm{t}}\right) \mathrm{HNO}_{3} / \mathrm{HF}$.

For TIMS analyses and upfront separation, 4 and $8 \mathrm{~mol} \mathrm{~L}^{-1}$ nitric acid solutions were prepared by diluting high purity nitric acid (Merck, Suprapur) with deionised water. For the separation protocol, an elution solution consisted of $\left(4 \mathrm{~mol} \mathrm{~L}^{-1} / 0.1 \mathrm{~mol} \mathrm{~L}{ }^{-1}\right) \quad \mathrm{HNO}_{3} / \mathrm{H}_{2} \mathrm{C}_{2} \mathrm{O}_{4}$ mixture. It was prepared by diluting nitric acid with deionized water and by weighing dihydrated oxalic acid.

UTEVA resins (Triskem ${ }^{\circledR}$, USA, 100-150 $\mu$ m particle size in $2 \mathrm{~mL}$ prepackaged columns) were used in the separation protocol in order to obtain a pure zirconium fraction.

\section{Precipitation experiment}

Dissolution solutions of irradiated $\mathrm{UO}_{x}$ fuel were obtained after heating for $30 \mathrm{~min}$ hulls at $85{ }^{\circ} \mathrm{C}$ in initial solution consisting of $6.6 \mathrm{~mol} \mathrm{\textrm {L } ^ { - 1 }}$ nitric acid. $\mathrm{Zr}$ and Mo concentrations were approximatively 2 and $1 \mathrm{~g} \mathrm{~L}^{-1}$, respectively. The solutions were heated under reflux over a few hours to dissolve the fuel. $\mathrm{Zr}$ was then let precipitating as zirconium molybdate for about $40 \mathrm{~h}$. Aliquots were sampled on a regular basis during the precipitation experiment. To stop precipitation, samples were diluted and acidified in $5 \mathrm{~mol} \mathrm{~L}^{-1} \mathrm{HNO}_{3}$ gravimetrically right after being collected. Samples were stored in this matrix until being used. This experiment was performed on two different initial solutions (hereafter referred to as solution 1 and solution 2 ). Once the dissolution was complete, solutions are called dissolution solution.

\section{Solutions and samples preparation}

Initial solutions were prepared gravimetrically in a gauged flask, in order to validate density and consisted of $6.6 \mathrm{~mol} \mathrm{~L}^{-1} \mathrm{HNO}_{3}$. In order to reduce uncertainties and follow dilution factors for ICP-MS measurements, it was spiked with $100 \mathrm{mg} \mathrm{L}^{-1}$ lutetium (hereafter referred to as process internal standard). Indeed, it is time consuming to weigh samples in a shielded cell, thus it was decided to follow a process internal standard and perform volumetric dilutions. It was verified lutetium has no influence on zirconium separation. Results for ICP-MS would be given relatively to $\mathrm{Lu}$.

For ICP-MS, an approximate (as Lu is present as process internal standard) 5000-fold dilution was performed in a shielded facility to reduce radiation level. Afterwards, a 100 -fold dilution was performed in a glove box leading to a 500,000-fold dilution.

Tests were performed on non-interfered isotopes using natural elements standard solutions beforehand: ${ }^{90} \mathrm{Zr}$ and ${ }^{98} \mathrm{Mo}$.

However, for TIMS, such a dilution could not be performed as the amount-of-substance would not have been sufficient, thus a separation was necessary to remove isobars as well as emitting elements. For TIMS analysis, a separation step is required to obtain a pure $\mathrm{Zr}$ fraction in order to eliminate all interfering elements (such as Mo). It also helps decreasing the radiation level mainly due to cesium and actinides present in the sample to obtain a radiation level of the solution compatible with glove box work. This separation was performed in shielded cell. It was described entirely by Quemet et al. [10]. The sample, previously diluted with $8 \mathrm{~mol} \mathrm{~L}^{-1}$ nitric acid and deionized water in order to obtain a $4 \mathrm{~mol} \mathrm{~L}^{-1}$ nitric acid matrix, was deposited onto the column. The column was then washed with $4 \mathrm{~mol} \mathrm{~L}^{-1} \mathrm{HNO}_{3}$ in order to eliminate all interfering elements (the $\mathrm{Zr}$ is extracted on the column). Zirconium was eluted with a $\mathrm{HNO}_{3} / \mathrm{H}_{2} \mathrm{C}_{2} \mathrm{O}_{4}$ mixture. After the separation, the elution solution was transferred to the TIMS analysis laboratory by pneumatic transfer. The elution solution was then evaporated and re-dissolved with nitric acid in order to obtain a $\mathrm{Zr}$ concentration around $5 \mu \mathrm{g} \mu \mathrm{L}^{-1}$. Then, $1 \mu \mathrm{L}$ of this solution was deposited onto the filament for the isotope analysis.

For the sample isotope analysis, one separation was performed in the shielded cell. Then, 3 independent isotope analyses were performed by TIMS. Zirconium concentration determination was performed by isotope dilution. For each concentration determination, 3 sample-tracer mixtures were prepared gravimetrically with $200 \mu \mathrm{L}$ of tracer (natural $\mathrm{Zr}$ SPEX solution at $1000 \mu \mathrm{g} \mathrm{L}^{-1}$ ) and $250 \mu \mathrm{L}$ of sample. The separation step was performed on the 3 mixtures before the isotope analysis. 


\section{Instruments}

The ICP-MS measurements were performed on an Elan DRCe (PerkinElmer, USA) equipped with a glove box. Plasma conditions were verified $30 \mathrm{~min}$ after start up and optimised if needed. A Meinhard ${ }^{\circledR}$ concentric nebuliser was used with a low volume baffled cyclonic spray chamber. To avoid any measurement delays or carry over, uptake and rinse parameters were optimized (Table 1). In order to obtain the lowest RSD possible and limit sample consumption 60 replicates were performed. Samples were analysed using peak hopping and integration time was set to $50 \mathrm{~ms} \mathrm{amu}^{-1}$. Ytterbium was used as an analytical internal standard to monitor plasma variations. As $\mathrm{Zr}$ was a fission product, its occurring isotopes are: 90, 91, 92, 93, 94, 95 and $96 .{ }^{90} \mathrm{Zr}$ being interfered by ${ }^{90} \mathrm{Sr}$ and ${ }^{93} \mathrm{Zr}$ by ${ }^{93} \mathrm{Nb}$, isotope 92 and 94 were measured for the kinetics experiments to avoid isobar interferences.

Description of filament loading techniques and details on the TIMS Thermo Fischer Triton instrument (Waltham, MA, United States) are given by Quemet et al. [10, 11]. Concentration analysis by isotope dilution was performed with this developed method [10] while the isotope composition was determined using the classical method.

\section{Zirconium concentration determination by isotope dilution}

The zirconium concentration determination was performed using isotope dilution. The equation for the sample concentration determination is defined by Eq. 1.

$$
\begin{aligned}
{[\mathrm{Zr}]_{\mathrm{S}}=} & {[\mathrm{Zr}]_{\mathrm{T}} \times \frac{m_{\mathrm{T}}}{m_{\mathrm{S}}} \times \frac{M_{\mathrm{S}}}{M_{\mathrm{T}}} \times \frac{(90)_{\mathrm{T}}}{(91)_{\mathrm{S}}} } \\
& \times \frac{(90 / 91)_{\text {Mix }}-(91 / 90)_{\mathrm{T}}}{1-(91 / 90)_{\text {Mix }} \times(90 / 91)_{\mathrm{S}}}
\end{aligned}
$$

where $T$ refers to the tracer used with the major isotope 90 , Mix refers to the sample-tracer mixture and $S$ refers to the sample; $m$ are the masses involved in the mixture; $M$ are the atomic weights; (90) and (91) are the isotope abundances of each major isotope; 90/91 and 91/90 are the isotope ratios.

For ICP-MS analysis, the most important contribution to uncertainties is the dilution factors. Here, the experiments were performed in a shielded line and the analysis in a glove box. Thus, the average dilution factor was 500,000fold. That is why the initial solution $\left(\sim 6 \mathrm{M} \mathrm{HNO}_{3}\right)$ was spiked with lutetium, in order to be able to compute a ratio between intensities (Eq. 2). It would allow following the evolution of concentration as $\mathrm{Zr}$ precipitates between $t_{0}$ and $t_{\mathrm{f}}$.

$R=\frac{Z r(c p s)}{L u(c p s)}$

With $\mathrm{Zr}(\mathrm{cps})$ : $\mathrm{Zr}$ intensity in count $\mathrm{s}^{-1}$; Lu(cps): lutetium intensity in count $\mathrm{s}^{-1} ; R$ ratio

Uncertainties associated with such a ratio depend only on the relative standard deviation (RSD) (Eq. 3):

$U_{\mathrm{R}}=2 \times \frac{\mathrm{RSD}(R)}{\sqrt{\text { number of replicates }}}$

With $R$ ratio; $\mathrm{RSD}=\frac{\sigma(X)}{\bar{X}} \bar{X}$ average intensity; $\mathrm{U}_{\mathrm{R}}$ expanded uncertainties

The kinetics evolution $\Delta$ is expressed by Eq. 4 :

$\Delta=\frac{X_{\mathrm{t}_{0}}-X_{\mathrm{t}_{\mathrm{f}}}}{X_{\mathrm{t}_{0}}}$

With $\Delta \mathrm{Zr}$ evolution; $X$ concentration for TIMS and ratio for ICP-MS; $t_{0}$ starting time; $t_{\mathrm{f}}$ end time.

Uncertainties estimation for the evolution $(\Delta)$ follows Eq. 5 for ICP-MS measurements:

$U_{\Delta}=2 \times \sqrt{\frac{R_{t_{\mathrm{f}}}^{2}}{R_{t_{0}}^{4}} \cdot u^{2}\left(R_{t_{0}}\right)+\frac{1}{R_{t_{0}}^{2}} \cdot u^{2}\left(R_{t_{\mathrm{f}}}\right)}$

where $U$ expanded uncertainty; $u$ uncertainties; $R$ ratio

\section{Results and discussion}

TIMS analysis in such a set up allows for low uncertainties, however it is time consuming and not adapted for quick kinetics analysis. Thus, only the first $\left(t_{0}\right)$ and final $\left(t_{\mathrm{f}}\right)$ samples were analysed this way. The kinetics core samples were analysed by ICP-MS relatively to the process internal standard put into the initial solution (Lu).

Table 1 Sampling parameters

\begin{tabular}{llll}
\hline & Solution & Time & Flow rate \\
\hline Sampling & & & \\
Uptake & Sample in $(2 \% / 0.01 \%) \mathrm{HNO}_{3} / \mathrm{HF}$ & $20 \mathrm{~s}$ & $5 \mathrm{~mL} \mathrm{~min}^{-1}$ \\
Stabilisation & Sample in $(2 \% / 0.01 \%) \mathrm{HNO}_{3} / \mathrm{HF}$ & $10 \mathrm{~s}$ & $1 \mathrm{~mL} \mathrm{~min}^{-1}$ \\
Rinse & $(10 \% / 0.01 \%) \mathrm{HNO}_{3} / \mathrm{HF}$ & $20 \mathrm{~s}$ & $5 \mathrm{~mL} \mathrm{~min}^{-1}$ \\
\hline
\end{tabular}


Fig. 1 a $\mathrm{Zr}$ measurement in presence of $\mathrm{Mo}$ in $2 \% \mathrm{HNO}_{3}$ matrix, $\mathbf{b} \mathrm{Zr}$ measurement in presence of Mo in 10\%/0.01\% $\mathrm{HNO}_{3} / \mathrm{HF}$ matrix$[\mathrm{Zr}]=[\mathrm{Mo}]=10 \mu \mathrm{g} \mathrm{L}^{-1}$

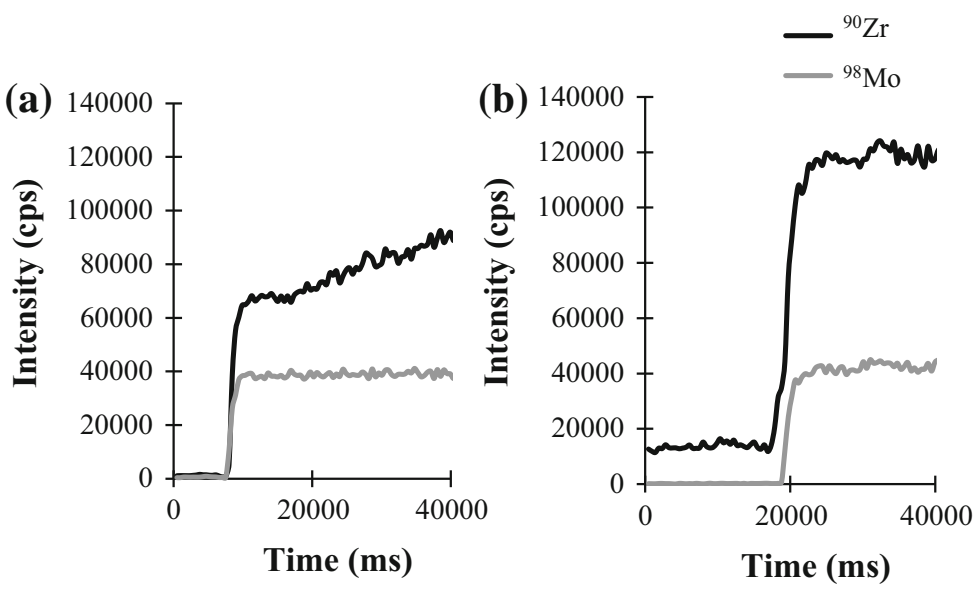

\section{Optimisation of ICP-MS analytical parameters}

For ICP-MS analysis of intermediary samples, the dilution matrix is usually $2 \% \mathrm{HNO}_{3}\left(w_{\mathrm{t}}\right)$. Natural Mo and $\mathrm{Zr}$ were mixed at a concentration of $10 \mu \mathrm{g} \mathrm{L}^{-1}$. However, zirconium shows lagging tendencies in presence of other elements in such medium (Fig. 1a). Solutions often contain hydrofluoric acid or oxalic acid for ICP analysis [12-14]. Oxalic acid cannot be used where it can be avoided as it is quite difficult to deal with as an analytical effluent in the nuclear fuel cycle, so HF was chosen. Its concentration being limited as well a $2 \% / 0.01 \% \mathrm{HNO}_{3} / \mathrm{HF}$ mixture was used and found efficient to stabilize $\mathrm{Zr}$ (Fig. 1b). $\mathrm{HNO}_{3}$ concentration was increased up to $10 \%$ in the rinse solution to avoid any carryover.

Figure 2 shows the evolution of the ratio uncertainty $\left(U_{\mathrm{R}}\right)$ as the number of replicates increases for ICP-MS measurements. $\mathrm{Zr}$ at $10 \mu \mathrm{g} \mathrm{L}^{-1}$ was mixed with $\mathrm{Mo}$ at $10 \mu \mathrm{g} \mathrm{L}^{-1}$ in a $\mathrm{HNO}_{3} / \mathrm{HF}$ solution. It leads to a lower uncertainty as the number of replicates increases. It seems that increasing the number of replicates further would lead to a better uncertainty as the RSD would be lower but the sample consumption would increase dramatically. Thus, a total number of replicates was set to 60 .

These optimised parameters were used to analyse the aliquots sampled during the kinetics.

\section{Kinetics}

Two different dissolution solutions were analysed through time. TIMS results and associated uncertainties are presented in Table 2. Concentration evolution $(\Delta)$ is about

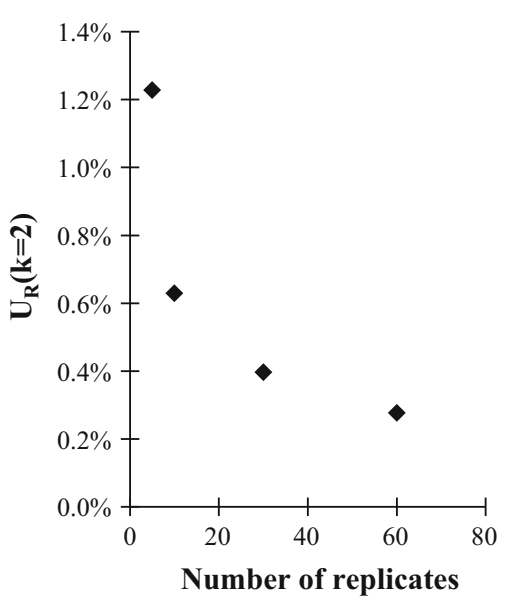

Fig. 2 Evolution of the ratio expanded uncertainty with the number of replicates. $[\mathrm{Zr}]=10 \mu \mathrm{g} \mathrm{L}^{-1}$ and $[\mathrm{Mo}]=10 \mu \mathrm{g} \mathrm{L}^{-1}$ in the dilution matrix

$20 \%$ in both cases. Uncertainties are lower than $3 \%$ on each sample except for $t_{\mathrm{f}}$ on solution 2 (3.4\%). However, they are higher than the one presented in the previous paper [10]. Indeed, the first study was performed on an idealistic case. Here, the sample was spiked gravimetrically on a scale in a shielded cell which is less accurate than the one the glove box where the TIMS analysis is performed. It strongly affected the uncertainties estimations.

For solution 2, uncertainties for TIMS analyses are slightly more important than the ones for solution 1 as uncertainties are more important for this solution analyses. Indeed, these solutions were stored a while longer than solution 1. Despite the stabilisation step they may have not
Table 2 Initial and final sample concentrations by TIMS

\begin{tabular}{lllll}
\hline & Solution 1 & $\Delta$ & Solution 2 & $\Delta$ \\
\hline$t_{0}$ & $1.258 \pm 0.023 \mathrm{mg} \mathrm{g}^{-1}$ & $(19.5 \pm 2.2) \%$ & $1.299 \pm 0.020 \mathrm{mg} \mathrm{g}^{-1}$ & $(18.2 \pm 3.1) \%$ \\
$t_{\mathrm{f}}$ & $1.013 \pm 0.020 \mathrm{mg} \mathrm{g}^{-1}$ & & $1.063 \pm 0.036 \mathrm{mg} \mathrm{g}^{-1}$ & \\
\hline
\end{tabular}




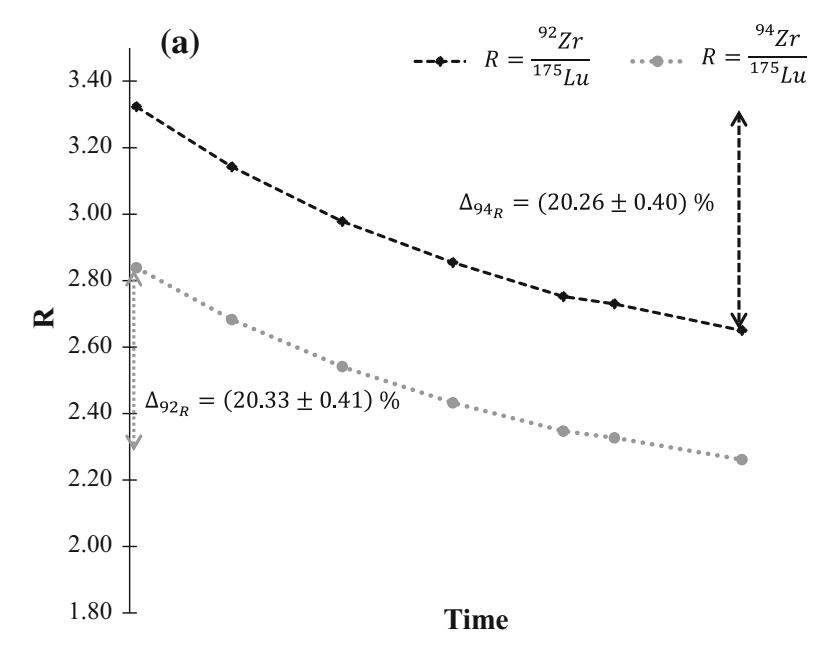

(b)

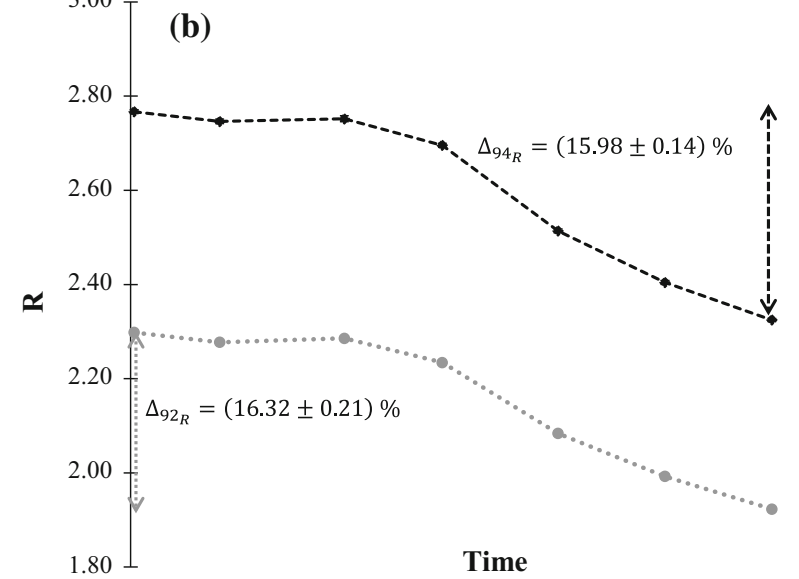

Fig. 3 Ratio (Eq. 2) evolution through time for a solution 1 and b solution 2

been completely stable as it has been noticed in previous unpublished studies.

As $\mathrm{Zr}$ isotope composition was not natural, 92 and 94 isotopes were measured by ICP-MS. Figure 3 shows the ICP-MS results obtained. Uncertainties on each ratio is too small to be seen on this plot (lower than 1\%). Time has been randomised for confidentiality purposes. Uncertainties are below $2 \%$. It is enough to consider each sample is different from the one before it, making the differences of kinetics shape significant.

ICP-MS results are in good agreement with the TIMS ones regarding evolution $(\Delta)$. $\mathrm{Zr}$ concentration is reduced by about $\quad \Delta_{94_{\mathrm{R}}}=(20.26 \pm 0.40) \%$ and $\quad \Delta_{92_{\mathrm{R}}}=$ $(20.33 \pm 0.41) \%$ between the starting and the final kinetics sample for solution 1 , and $\Delta_{94_{R}}=(15.98 \pm 0.14) \%$ and $\Delta_{92_{\mathrm{R}}}=(16.32 \pm 0.21) \%$ for solution 2 .

Uncertainties obtained by ICP-MS for evolutions are $2.0,2.0,0.85$ and $1.26 \%$ respectively. They are significantly lower than the one obtained by TIMS. This phenomenon can be explained by the fact gravimetric spiking does not have to be taken into account for ICP-MS measurements.

\section{Analytical management}

It was chosen to differentiate the two analyses (i.e. initial and final sample by TIMS, and evolution by ICP-MS), not only because of time consumption but also because of effluent and waste management. Table 3 shows the practical parameters obtained and the interest of not analysing all samples by TIMS.

The method presented here is more cost-effective than the one using only TIMS. Indeed, high level effluent generation was reduced by three quarter, some medium level effluents were generated instead and working hours, in shielded line especially, were reduced by half.

It is a quite important factor as high level effluents and wastes are difficult to deal with, in regard of storage and evacuation, work conditions in shielded line are more strenuous than in glove boxes and performing experiments in the latter should always be preferred whenever possible.

Table 3 Practical parameters

\begin{tabular}{lllll}
\hline & All sample by TIMS & \multicolumn{2}{l}{ Presented technique } \\
\cline { 3 - 4 } & & TIMS & ICP-MS & Total \\
\hline Waste management & & & \\
$\quad$ Generated effluents & $840 \mathrm{~mL} \mathrm{HC}$ & $240 \mathrm{~mL} \mathrm{HC}$ & $360 \mathrm{~mL} \mathrm{~GB}$ & $600 \mathrm{~mL}$ \\
$\quad$ Number of separations & $42 \mathrm{HC}$ & $13 \mathrm{HC}$ & 0 & 13 \\
Working hours & & & & \\
$\quad$ Separation & $64 \mathrm{~h} \mathrm{HC}$ & $40 \mathrm{~h} \mathrm{HC}$ & $0 \mathrm{~h}$ & $40 \mathrm{~h}$ \\
Sample weighing & $7 \mathrm{~h} \mathrm{HC} / \mathrm{GB}$ & $2 \mathrm{~h} \mathrm{HC} / \mathrm{GB}$ & $0 \mathrm{~h}$ & $2 \mathrm{~h}$ \\
$\quad$ Measurements and sample preparation & $68 \mathrm{~h} \mathrm{~GB}$ & $20 \mathrm{~h} \mathrm{~GB}$ & $14 \mathrm{~h} \mathrm{~GB}$ & $34 \mathrm{~h}$ \\
Total & $139 \mathrm{~h}$ & $76 \mathrm{~h}$ & & \\
\hline
\end{tabular}

$G B$ glove box, $H C$ hot cell 


\section{Conclusions}

Spiking sample at the beginning of the kinetics experiment and analysing the sample either by TIMS or by ICP-MS allows for low uncertainties and rapid analysis of zirconium. As no other information than the measured isotope intensity is necessary, computing a ratio by ICP-MS allows for uncertainties lower than the one obtained by TIMS for concentration evolution. Thus combining TIMS and ICPMS allows answering quantitatively when kinetics shapes are required, giving the initial and final concentration and the kinetics evolution with uncertainties lower than $3 \%$.

Acknowledgements The authors would like to thank Dr Pascal Fichet (DEN/DANS/DPC/SEARS/LASE) for computation files, Ms Valérie Boyer-Delys (DMRC/SA2I/L2AT) for her help.

\section{References}

1. Matsuo Y, Suda Y, Suda N (1989) Highly corrosion-resistant zirconium alloy for use as nuclear reactor fuel cladding material. U.S. Patent and Trademark Office, Washington, DC

2. Osváth S, Vajda N, Stefánka Z et al (2011) Determination of $93 \mathrm{Zr}$ and $237 \mathrm{~Np}$ in nuclear power plant wastes. J Radioanal Nucl Chem 287:459-463. https://doi.org/10.1007/s10967-010-0886-9

3. Kubota M, Fukase T (1980) Formation of precipitate in highlevel liquid waste from nuclear fuel reprocessing. J Nucl Sci Technol 17:783-790. https://doi.org/10.1080/18811248.1980. 9732654

4. Kmonk S, Mayers J (1969) Fuel assembly for a nuclear reactor using zirconium alloy clad fuel rods. U.S. Patent 3,719,560

5. Lustman B, Bleiberg ML, Byron ES et al (1961) Zircaloy cladding performs well in PWR. Ceased Publ, Nucleon
6. Mardon J-P, Charquet D, Perez M, Senevat J (1990) Rod for a fuel assembly of a nuclear reactor resisting corrosion and wear. U.S. Patent 5,023,048

7. Magnaldo A, Masson M, Champion R (2007) Nucleation and crystal growth of zirconium molybdate hydrate in nitric acid. Chem Eng Sci 62:766-774. https://doi.org/10.1016/j.ces.2006.08. 076

8. Esbelin E (2014) Graphite monochromator for actinide L-line energy dispersive X-ray fluorescence analysis in liquid sample. X-Ray Spectrom 43(4):198-208. https://doi.org/10.1002/xrs.2540

9. Chartier F, Isnard H, Degros JP et al (2008) Application of the isotope dilution technique for $93 \mathrm{Zr}$ determination in an irradiated cladding material by multiple collector-inductively coupled plasma mass spectrometry. Int J Mass Spectrom 270:127-133. https://doi.org/10.1016/j.ijms.2007.12.005

10. Quemet A, Maillard C, Ruas A (2015) Determination of zirconium isotope composition and concentration for nuclear sample analysis using thermal ionization mass spectrometry. Int $\mathrm{J}$ Mass Spectrom 392:34-40. https://doi.org/10.1016/j.ijms.2015.08.023

11. Quemet A, Maloubier M, Ruas A (2016) Contribution of the Faraday cup coupled to $1012 \Omega$ current amplifier to uranium $235 / 238$ and $234 / 238$ isotope ratio measurements by thermal ionization mass spectrometry. Int J Mass Spectrom 404:35-39. https://doi.org/10.1016/j.ijms.2016.04.005

12. Kunze J, Koelling S, Reich M, Wimmer MA (1998) ICP-MS determination of titanium and zirconium in human serum using an ultrasonic nebulizer with desolvator membrane. At Spectrosc 19:164-167

13. Poehle S, Schmidt K, Koschinsky A (2015) Determination of Ti, $\mathrm{Zr}, \mathrm{Nb}, \mathrm{V}, \mathrm{W}$ and Mo in seawater by a new online-preconcentration method and subsequent ICP-MS analysis. Deep Res Part I Oceanogr Res Pap 98:83-93. https://doi.org/10.1016/j.dsr.2014. 11.014

14. Gautier C, Coppo M, Caussignac C et al (2013) Zr and U determination at trace level in simulated deep groundwater by $\mathrm{Q}$ ICP-MS using extraction chromatography. Talanta 106:1-7. https://doi.org/10.1016/j.talanta.2012.12.019 